\title{
Change in daily energy intake associated with pairwise compositional change in carbohydrate, fat and protein intake among US adults, 1999-2010
}

\author{
Ruopeng $\mathrm{An}^{1, *}$ and Nicholas A Burd ${ }^{2}$ \\ 'Department of Kinesiology and Community Health, College of Applied Health Sciences, University of Illinois at \\ Urbana-Champaign, 1206 S. 4th Street, Champaign, IL 61820, USA: ${ }^{2}$ Department of Kinesiology and Community \\ Health, Division of Nutritional Sciences, University of Illinois at Urbana-Champaign, Champaign, IL, USA
}

Submitted 21 March 2014: Final revision received 29 June 2014: Accepted 29 July 2014: First published online 5 September 2014

\begin{abstract}
Objective: To assess the change in daily energy intake associated with pairwise compositional change in carbohydrate, fat and protein intake among US adults stratified by sex, race/ethnicity and weight status.

Design: Linear mixture model was performed to estimate the relationship between daily energy intake and macronutrient composition, adjusted for age and alcohol consumption, and accounting for survey design.

Setting: Study sample from the National Health and Nutrition Examination Survey, 1999-2010 waves.

Subjects: A total of 27589 US adults aged 20 years and older were included in the study. Dietary macronutrient intake was calculated from $24 \mathrm{~h}$ dietary recall and BMI from objectively measured weight/height.

Results: Across all population subgroups, substituting protein or carbohydrate for fat and substituting protein for carbohydrate were associated with decreased daily energy intake, with the largest effect resulting from substituting protein for fat. A $1 \%$ increase in the percentage of energy from protein substituted for a $1 \%$ decrease in the percentage of energy from fat was associated with a decrease in daily energy intake of $268 \cdot 2$ (95\% CI 169.0, 367.4) kJ, $289 \cdot 5$ (95\% CI 215.9, 363.2) $\mathrm{kJ}$ and 293.7 (95\% CI 210.0, 377.4) kJ among normal-weight (18.5 $\leq \mathrm{BMI}$, $\left.\mathrm{kg} / \mathrm{m}^{2}<25 \cdot 0\right)$, overweight $\left(25 \cdot 0 \leq\right.$ BMI, $\left.\mathrm{kg} / \mathrm{m}^{2}<30 \cdot 0\right)$ and obese (BMI $\geq 30 \cdot 0$ $\mathrm{kg} / \mathrm{m}^{2}$ ) men, and $177 \cdot 4(95 \%$ CI $130 \cdot 5,224 \cdot 3) \mathrm{kJ}, 188 \cdot 7$ (95\% CI 139.3, 238.1) kJ and 204.2 (95\% CI 158.2, 250.2) kJ among normal-weight, overweight and obese women, respectively. The relationship between macronutrient composition and daily energy intake varied substantially across sex, race/ethnicity and weight status. Conclusions: Policies promoting higher daily protein intake at the expense of lower fat intake could be effective in reducing total energy intake among US adults.
\end{abstract}

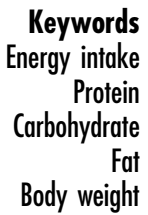

Keywords Protein Fat Body weight
Obesity is a leading risk factor for many adverse health outcomes including type 2 diabetes, hypertension, dyslipidaemia, CHD and certain types of cancer ${ }^{(1)}$. The prevalence of adult obesity in the USA more than doubled from 1976-1980 to 2011-2012 $2^{(2,3)}$ and it has increased in both men and women as well as across all racial/ethnic groups ${ }^{(4)}$. In 2009, the estimated annual cost of obesity approached \$US 300 billion, including \$US 173 billion in lost productivity and \$US 127-147 billion in medical expenditures ${ }^{(5,6)}$.

Body weight is governed, at least partly, by the energy content of the diet. Diets of different macronutrient compositions have been documented to affect total daily energy intake and body weight in many randomized trials ${ }^{(7-11)}$. In particular, controlled energy intake accompanied by a moderately elevated protein intake appears to be an effective and practical weight-management strategy, mainly through increased satiety and thermogenesis, and maintenance or accretion of fat-free mass (muscle) ${ }^{(12)}$. Skeletal muscle plays a major role in determining BMR, which is the main component of daily total energy expenditure for most individuals ${ }^{(13)}$.

Despite the growing evidence on the relationship between macronutrient composition and energy intake or body weight from small-scale experiments, relevant populationlevel studies remain relatively scarce. Ford and Dietz ${ }^{(14)}$ documented trends in carbohydrate, fat and protein intakes among US adults from 1971-1975 to 2009-2010 using data from the National Health and Nutrition Examination Survey (NHANES), noting a decrease in dietary energy intake in 
recent years. Austin et al. ${ }^{(15)}$ estimated and compared the associations between macronutrient composition and energy intake by body weight status and across NHANES wave (1971-1975 v. 2005-2006). Their study demonstrated that substituting dietary protein for fat or carbohydrate was associated with lower daily total energy intake. However, it did not directly assess the impact of macronutrient substitutions on dietary energy intake in genderspecific minority groups. Evidence suggests that there are clear racial disparities in the prevalence of overweight/ obesity in the American population ${ }^{(4)}$.

Heterogeneity in macronutrient intake and energy consumption across sex and race/ethnicity has been extensively documented, but the underlying mechanisms remain less well understood. Leblanc et al. ${ }^{(16)}$ reported higher energy intake, energy density and percentage of energy from fats, and lower percentage of energy from carbohydrates, in men than in women and the disparity appeared to be associated with sex differences in eatingrelated self-determined motivation. There was some but mixed evidence on the relationship between sex differences in energy metabolism and sex steroids, differences in insulin resistance, metabolic effects of other hormones such as leptin, and acute energy intake regulation ${ }^{(17-21)}$. Using data from a nationally representative health survey, Wang and Chen ${ }^{(22)}$ investigated the extent to which racial/ethnic disparities in dietary intakes could be explained by nutritionand health-related psychosocial factors and socio-economic status among US adults. Differences in diet were evident between racial/ethnic groups, but few of these disparities were explained by nutrition- and health-related psychosocial factors whereas socio-economic status explained some.

The aim of the present study was to examine the change in daily energy intake associated with pairwise compositional change in dietary carbohydrate, fat and protein intake among US adults aged 20 years and older, using a nationally representative sample from NHANES 1999-2010 waves. Given the possible heterogeneity in the relationship between macronutrient intake and energy consumption, we conducted subgroup analyses, stratifying the study sample by sex, race/ethnicity and body weight status.

\section{Methods}

\section{Study sample}

Individual-level data came from NHANES 1999-2000, 2001-2002, 2003-2004, 2005-2006, 2007-2008 and 20092010 waves. NHANES is a programme of studies designed to assess the health and nutritional status of adults and children and represents a multistage probability sample of the US civilian, non-institutionalized population ${ }^{(23)}$. The NHANES programme began in the early $1960 \mathrm{~s}$ and periodically conducted separate surveys focusing on different population groups or health topics. Since 1999, NHANES has been conducted continuously in 2-year cycles and has a changing focus on a variety of health and nutrition measurements.

Demographic information such as sex, age and race/ ethnicity (non-Hispanic White; non-Hispanic African American; non-Hispanic other race/multi-race; Hispanic) was collected through in-person interview. NHANES respondents' body weight and height were measured by digital scale and stadiometer in the mobile examination centre. Among the 32464 adults aged 20 years and older who participated in NHANES 1999-2010 waves, 2040 of them were either pregnant or on a special diet to lose weight at the time of interview and were excluded from analyses. We further excluded 2835 individuals with missing information on body weight/height and/or dietary measures. This resulted in a total effective sample size of 27589 .

\section{Dietary recall}

Except for NHANES 1999-2000 wave where all respondents were asked to complete a single $24 \mathrm{~h}$ dietary recall interview, all subsequent waves incorporate two dietary recalls, with the first collected in-person and the second by telephone 3 to $10 \mathrm{~d}$ later. In both interviews, each food item and the corresponding quantity consumed by a respondent from midnight to midnight on the day before the interview were recorded. The in-person dietary recall was conducted by trained dietary interviewers in the mobile examination centre with a standard set of measuring guides. These tools aim to help the respondent accurately report the volume and dimensions of the food items consumed. Upon completion of the in-person interview, participants were provided measuring cups, spoons, a ruler and a food model booklet, which contain two-dimensional drawings of the various measuring guides available in the mobile examination centre, to use for reporting dietary intake during the telephone interview. Due to confidentiality concerns, for NHANES 2001-2002 wave, only in-person dietary recall data were released. For all subsequent waves, both in-person and telephone dietary recall data were publicly available.

NHANES $24 \mathrm{~h}$ dietary recall data have been extensively used by government agencies and researchers for the purposes of public health surveillance, dietary guideline formulation and public health policy design. To ensure data quality and reduce measurement errors, rigorous quality control protocols have been implemented for reviewing and coding dietary recall data ${ }^{(24)}$. Nevertheless, methodological limitations have been reported to compromise the validity of NHANES nutritional surveillance data $^{(25)}$. Under-reporting of dietary intake appeared to be most salient among obese participants.

\section{Energy intake and body weight status}

Daily total energy intake (kJ) from carbohydrate, fat, protein and alcohol was calculated based on the consumed quantity (gram) recorded in the dietary recall data. For NHANES 1999-2000 and 2001-2002 waves, only in-person dietary 
recall data were used, whereas for all subsequent waves data from in-person and telephone interviews were averaged. Macronutrient compositions are defined as the share (percentage) of energy from carbohydrate, fat, protein and alcohol in daily total energy intake.

BMI is defined by weight in kilograms divided by height in metres squared. Normal weight is defined as $18.5 \leq \mathrm{BMI}$, $\mathrm{kg} / \mathrm{m}^{2}<25 \cdot 0$, overweight as $25 \cdot 0 \leq \mathrm{BMI}, \mathrm{kg} / \mathrm{m}^{2}<30 \cdot 0$ and obese as BMI $\geq 30 \cdot 0 \mathrm{~kg} / \mathrm{m}^{2}$. Excess weight refers to the status of overweight or obese with BMI $\geq 25 \cdot 0 \mathrm{~kg} / \mathrm{m}^{2}$.

\section{Statistical analysis}

We summarized the mean age, BMI, daily total energy intake, energy from carbohydrate, fat, protein and alcohol, and their respective share in total energy intake among the US adult population during 1999-2010. Separate statistics are reported for each sex, race/ethnicity (non-Hispanic White, non-Hispanic African American, Hispanic; other races/ethnicities were excluded due to small sample size) and body weight status (normal weight, overweight, obese).

Multiple linear regression analyses were performed to estimate the change in daily total energy intake associated with pairwise compositional change in carbohydrate, fat and protein intake. The dependent variable was daily total energy intake, and the independent variables were percentages of energy from carbohydrate, fat, protein and alcohol, and their interactions (six two-way interactions, three three-way interactions and one four-way interaction). This model is known as the Scheffé linear mixture model, which has been widely used to model compositional or mixture data ${ }^{(26)}$. Detailed introduction about the model is documented in Cornell ${ }^{(27)}$. Austin et $a l^{(15)}$ applied the Scheffé linear mixture model to study the relationship between macronutrient intake and daily energy consumption among American adults. In our multiple linear regressions, age in years and age squared were controlled in the model to account for the potential non-linear ageing effect on diet. Separate models were estimated for each sex, race/ ethnicity and body weight status. The change in daily total energy intake was estimated by simulating a $1 \%$ increase (decrease) in the percentage of energy from one macronutrient accompanied by a $1 \%$ decrease (increase) in the percentage of energy from another macronutrient.

NHANES adopted a complex, multistage, probability sampling design to select participants representative of the civilian, non-institutionalized US population. Oversampling of certain population subgroups was performed to improve the reliability and precision of health status indicator estimates for these groups. NHANES sampling design was incorporated in all analyses using the 'svy' functions in Stata. Due to the use of multiple waves of NHANES data, we constructed proper sampling weights for combined survey cycles (six cycles in total from 1999-2010) following the procedures specified on the NHANES web portal ${ }^{(28)}$. We performed sub-population analysis on each sub-sample stratified by sex, race/ethnicity and body weight status using the 'subpopulation' option of 'svy' functions. All statistical analyses were conducted using the statistical software program Stata $13 \cdot 1$ SE version.

\section{Results}

Table 1 reports the individual characteristics of the study sample by sex, race/ethnicity and body weight status. During 1999-2010, $71.3 \%$ of men and $63.3 \%$ of women aged 20 years and older were with excess weight (BMI $\geq$ $25 \mathrm{~kg} / \mathrm{m}^{2}$ ), and $30.5 \%$ of men and $34.6 \%$ of women were obese $\left(\mathrm{BMI} \geq 30 \cdot 0 \mathrm{~kg} / \mathrm{m}^{2}\right)$. Overweight and obesity prevalence differed substantially across race/ethnicity. Among men, Hispanics had the highest excess weight rate $(74.8 \%)$ whereas African Americans led the obesity rate (33.7\%). Among women, African Americans ranked the highest for both excess weight (79.5\%) and obesity prevalence (52.1\%).

Table 2 reports daily energy intake by sex, race/ethnicity and body weight status for US adults aged 20 years and older. Even after excluding individuals who were on a special diet to lose weight, overweight and obese adults tended to consume less kilojoules on a daily basis compared with their normal-weight counterparts, and this pattern held for all sub-populations stratified by sex and race/ethnicity. Normal-weight men on average consumed $11183 \mathrm{~kJ} / \mathrm{d}$, compared with 10677 and $10629 \mathrm{~kJ} / \mathrm{d}$ among overweight and obese men; and normal-weight women on average consumed $7712 \mathrm{~kJ} / \mathrm{d}$, compared with 7372 and $7599 \mathrm{~kJ} / \mathrm{d}$ among overweight and obese women, respectively. For energy composition, women had a higher proportion of energy intake from carbohydrate (49.9\%, 50.1\% and 49.6\% among normal-weight, overweight and obese females, compared with $48.7 \%, 47 \cdot 8 \%$ and $46.7 \%$ among their male counterparts, respectively) but a lower proportion of energy intake from alcohol $(2.6 \%, 2.0 \%$ and $1.2 \%$ among normalweight, overweight and obese females, compared with $4.4 \%$, $4.1 \%$ and $3.2 \%$ among their male counterparts, respectively). In contrast, the shares of fat and protein intake were similar between men and women.

Differential energy intake patterns were present across race/ethnicity. Compared with their African-American and Hispanic counterparts, Caucasian men consumed more kilojoules across different body weight status (11 452, 10898 and $10779 \mathrm{~kJ} / \mathrm{d}$ among normal-weight, overweight and obese Caucasian men, respectively). Among the normalweight and overweight female population, African Americans $(7940$ and $7571 \mathrm{~kJ} / \mathrm{d}$, respectively) tended to have higher energy intake than their Caucasian and Hispanic counterparts, whereas in the obese category, Caucasians $(7702 \mathrm{~kJ} / \mathrm{d})$ ranked the top. For energy composition, across sex and body weight status, Hispanics had a noticeably larger proportion of energy intake from carbohydrate and a smaller proportion from fat compared with their Caucasian and African-American counterparts. Energy from carbohydrate accounted for $50.4 \%$ and $52.4 \%$ of daily total energy intake among overweight Hispanic men and women, 
Table 1 Individual characteristics of the study sample by sex, race/ethnicity and body weight status: US adults aged 20 years and older ( $n$ 27589), NHANES 1999-2010

\begin{tabular}{|c|c|c|c|c|c|c|c|c|c|c|c|c|c|c|c|c|}
\hline \multirow[b]{3}{*}{ Variable* } & \multicolumn{4}{|c|}{ All } & \multicolumn{4}{|c|}{ Caucasian } & \multicolumn{4}{|c|}{ African American } & \multicolumn{4}{|c|}{ Hispanic } \\
\hline & \multicolumn{2}{|c|}{ Male } & \multicolumn{2}{|c|}{ Female } & \multicolumn{2}{|c|}{ Male } & \multicolumn{2}{|c|}{ Female } & \multicolumn{2}{|c|}{ Male } & \multicolumn{2}{|c|}{ Female } & \multicolumn{2}{|c|}{ Male } & \multicolumn{2}{|c|}{ Female } \\
\hline & Mean & SE & Mean & SE & Mean & SE & Mean & SE & Mean & SE & Mean & SE & Mean & SE & Mean & SE \\
\hline \multicolumn{17}{|c|}{ Normal weight $\left(18.5 \leq \mathrm{BMI}, \mathrm{kg} / \mathrm{m}^{2}<25.0\right)$} \\
\hline Sample size $(n)$ & \multirow{2}{*}{\multicolumn{2}{|c|}{$\begin{array}{l}3972 \\
28.67\end{array}$}} & \multirow{2}{*}{\multicolumn{2}{|c|}{$\begin{array}{r}4270 \\
36.68\end{array}$}} & \multirow{2}{*}{\multicolumn{2}{|c|}{1970}} & \multirow{2}{*}{\multicolumn{2}{|c|}{$\begin{array}{l}2490 \\
39.77\end{array}$}} & \multirow{2}{*}{\multicolumn{2}{|c|}{$\begin{array}{c}850 \\
31.97\end{array}$}} & \multirow{2}{*}{\multicolumn{2}{|c|}{$\begin{array}{c}562 \\
20 \cdot 49\end{array}$}} & \multirow{2}{*}{\multicolumn{2}{|c|}{$\begin{array}{c}902 \\
25 \cdot 22\end{array}$}} & \multirow{2}{*}{\multicolumn{2}{|c|}{$\begin{array}{c}933 \\
27.00\end{array}$}} \\
\hline Proportion in population (\%) & & & & & & & & & & & & & & & & \\
\hline Age (years) & $42 \cdot 35$ & 0.39 & $45 \cdot 18$ & 0.32 & 43.67 & 0.51 & $46 \cdot 44$ & 0.40 & 40.53 & 0.57 & $42 \cdot 03$ & 0.75 & $36 \cdot 26$ & 0.65 & 38.51 & 0.62 \\
\hline BMI $\left(\mathrm{kg} / \mathrm{m}^{2}\right)$ & 22.69 & 0.03 & $22 \cdot 24$ & 0.03 & $22 \cdot 76$ & 0.04 & $22 \cdot 20$ & 0.04 & $22 \cdot 36$ & 0.06 & $22 \cdot 40$ & 0.09 & 22.79 & 0.07 & 22.51 & 0.06 \\
\hline \multicolumn{17}{|c|}{ Overweight $\left(25.0 \leq \mathrm{BMI}, \mathrm{kg} / \mathrm{m}^{2}<30.0\right)$} \\
\hline Sample size $(n)$ & \multirow{2}{*}{\multicolumn{2}{|c|}{$\begin{array}{l}5697 \\
40 \cdot 84\end{array}$}} & \multirow{2}{*}{\multicolumn{2}{|c|}{$\begin{array}{l}4150 \\
28.70\end{array}$}} & \multirow{2}{*}{\multicolumn{2}{|c|}{$\begin{array}{l}2837 \\
41.29\end{array}$}} & \multirow{2}{*}{\multicolumn{2}{|c|}{$\begin{array}{c}1910 \\
28 \cdot 10\end{array}$}} & \multirow{2}{*}{\multicolumn{2}{|c|}{$\begin{array}{c}950 \\
34.31\end{array}$}} & \multirow{2}{*}{\multicolumn{2}{|c|}{$\begin{array}{c}779 \\
27.38\end{array}$}} & \multirow{2}{*}{\multicolumn{2}{|c|}{$\begin{array}{c}1723 \\
45.75\end{array}$}} & \multirow{2}{*}{\multicolumn{2}{|c|}{$\begin{array}{c}1311 \\
34 \cdot 19\end{array}$}} \\
\hline Proportion in population (\%) & & & & & & & & & & & & & & & & \\
\hline Age (years) & $46 \cdot 82$ & 0.27 & $49 \cdot 74$ & 0.38 & 48.79 & 0.36 & 52.00 & 0.46 & 44.92 & 0.58 & $46 \cdot 07$ & 0.48 & $40 \cdot 19$ & 0.45 & 43.07 & 0.65 \\
\hline BMI $\left(\mathrm{kg} / \mathrm{m}^{2}\right)$ & $27 \cdot 42$ & 0.02 & $27 \cdot 37$ & 0.03 & $27 \cdot 43$ & 0.03 & $27 \cdot 36$ & 0.04 & $27 \cdot 38$ & 0.04 & $27 \cdot 50$ & 0.05 & $27 \cdot 43$ & 0.04 & $27 \cdot 37$ & 0.05 \\
\hline \multicolumn{17}{|l|}{ Obese $\left(\mathrm{BMI} \geq 30.0 \mathrm{~kg} / \mathrm{m}^{2}\right)$} \\
\hline Sample size $(n)$ & & & 52 & & & & & & & & 14 & & & & & \\
\hline Proportion in population (\%) & & & & & & & & & & & 52 & & & & & \\
\hline Age (years) & $46 \cdot 75$ & 0.35 & $48 \cdot 45$ & 0.29 & 48.69 & 0.43 & $50 \cdot 60$ & 0.36 & $43 \cdot 84$ & 0.42 & $45 \cdot 74$ & 0.50 & $40 \cdot 21$ & 0.39 & 42.52 & 0.50 \\
\hline BMI $\left(\mathrm{kg} / \mathrm{m}^{2}\right)$ & 34.72 & 0.09 & $36 \cdot 35$ & $0 \cdot 10$ & 34.68 & 0.12 & $36 \cdot 13$ & 0.14 & $35 \cdot 68$ & 0.19 & 37.65 & 0.19 & 34.29 & 0.16 & 35.54 & 0.18 \\
\hline
\end{tabular}

NHANES, National Health and Nutrition Examination Survey.

${ }^{*}$ NHANES 1999-2010 multiyear complex survey design was incorporated in estimations (except for sample size) 
Table 2 Daily energy intake by sex, race/ethnicity and body weight status: US adults aged 20 years and older ( $n$ 27 589), NHANES 1999-2010

\begin{tabular}{|c|c|c|c|c|c|c|c|c|c|c|c|c|c|c|c|c|}
\hline \multirow[b]{3}{*}{ Variable* } & \multicolumn{4}{|c|}{ All } & \multicolumn{4}{|c|}{ Caucasian } & \multicolumn{4}{|c|}{ African American } & \multicolumn{4}{|c|}{ Hispanic } \\
\hline & \multicolumn{2}{|c|}{ Male } & \multicolumn{2}{|c|}{ Female } & \multicolumn{2}{|c|}{ Male } & \multicolumn{2}{|c|}{ Female } & \multicolumn{2}{|c|}{ Male } & \multicolumn{2}{|c|}{ Female } & \multicolumn{2}{|c|}{ Male } & \multicolumn{2}{|c|}{ Female } \\
\hline & Mean & SE & Mean & SE & Mean & SE & Mean & SE & Mean & SE & Mean & SE & Mean & SE & Mean & SE \\
\hline \multicolumn{17}{|l|}{ Normal weight } \\
\hline Total energy (kJ) & 11183.0 & $110 \cdot 1$ & $7712 \cdot 4$ & $56 \cdot 1$ & $11452 \cdot 0$ & $135 \cdot 6$ & $7744 \cdot 6$ & 69.9 & 10844.9 & $207 \cdot 1$ & $7940 \cdot 4$ & $156 \cdot 9$ & $11078 \cdot 8$ & $200 \cdot 4$ & $7694 \cdot 0$ & $102 \cdot 5$ \\
\hline Carbohydrate (kJ) & $5387 \cdot 3$ & 54.4 & $3823 \cdot 8$ & $31 \cdot 8$ & 5468.9 & $72 \cdot 0$ & $3820 \cdot 0$ & 39.7 & $5137 \cdot 1$ & $93 \cdot 7$ & $3892 \cdot 0$ & $75 \cdot 3$ & $5555 \cdot 9$ & $110 \cdot 0$ & 3925.4 & 68.2 \\
\hline Carbohydrate (\%) & 48.7 & 0.2 & 49.9 & 0.2 & 48.2 & 0.3 & $49 \cdot 6$ & 0.2 & $48 \cdot 3$ & 0.4 & $49 \cdot 8$ & 0.5 & 50.7 & 0.5 & 51.4 & 0.5 \\
\hline Fat $(\mathrm{kJ})$ & $3608 \cdot 3$ & $40 \cdot 2$ & $2526 \cdot 3$ & $21 \cdot 3$ & 3740.5 & $49 \cdot 0$ & $2554 \cdot 3$ & $25 \cdot 9$ & $3551 \cdot 0$ & $90 \cdot 4$ & $2703 \cdot 3$ & 74.5 & $3410 \cdot 4$ & 84.5 & $2416 \cdot 3$ & $42 \cdot 3$ \\
\hline Fat $(\%)$ & $31 \cdot 8$ & 0.2 & $32 \cdot 3$ & 0.1 & $32 \cdot 4$ & 0.2 & $32 \cdot 7$ & 0.2 & $32 \cdot 0$ & 0.4 & 33.1 & 0.4 & $30 \cdot 3$ & 0.3 & $30 \cdot 8$ & 0.4 \\
\hline Protein (kJ) & $1646 \cdot 8$ & $17 \cdot 2$ & 1138.5 & $9 \cdot 6$ & 1661.9 & 21.8 & $1125 \cdot 5$ & $10 \cdot 9$ & $1592 \cdot 8$ & 31.0 & $1177 \cdot 0$ & 28.5 & $1677 \cdot 4$ & 33.5 & $1193 \cdot 3$ & 20.5 \\
\hline Protein (\%) & $15 \cdot 0$ & 0.1 & $15 \cdot 1$ & 0.1 & 14.8 & $0 \cdot 1$ & $14 \cdot 8$ & $0 \cdot 1$ & $15 \cdot 0$ & 0.2 & $15 \cdot 1$ & 0.3 & $15 \cdot 3$ & 0.2 & $15 \cdot 9$ & 0.2 \\
\hline Alcohol (kJ) & $540 \cdot 2$ & $32 \cdot 2$ & 223.8 & 11.7 & $580 \cdot 7$ & 41.0 & 244.8 & $15 \cdot 5$ & $564 \cdot 4$ & $57 \cdot 3$ & $168 \cdot 2$ & $20 \cdot 9$ & 434.7 & $39 \cdot 3$ & $159 \cdot 0$ & $19 \cdot 7$ \\
\hline Alcohol (\%) & 4.4 & 0.2 & 2.6 & $0 \cdot 1$ & 4.7 & 0.2 & 2.9 & 0.2 & 4.7 & 0.3 & $2 \cdot 0$ & 0.2 & 3.7 & 0.3 & 1.9 & 0.2 \\
\hline \multicolumn{17}{|l|}{ Overweight } \\
\hline Total energy (kJ) & $10677 \cdot 1$ & $80 \cdot 8$ & $7372 \cdot 2$ & 58.2 & $10897 \cdot 6$ & $104 \cdot 2$ & 7429.9 & $69 \cdot 0$ & $10185 \cdot 1$ & 178.7 & $7570 \cdot 9$ & 143.9 & $10219 \cdot 4$ & 128.9 & $7068 \cdot 9$ & $140 \cdot 6$ \\
\hline Carbohydrate (kJ) & $5059 \cdot 3$ & $42 \cdot 3$ & $3668 \cdot 1$ & 30.5 & 5094.4 & $55 \cdot 2$ & $3652 \cdot 2$ & $36 \cdot 8$ & 4871.0 & $92 \cdot 0$ & 3729.2 & $72 \cdot 8$ & $5084 \cdot 8$ & $76 \cdot 1$ & $3690 \cdot 7$ & 82.0 \\
\hline Carbohydrate (\%) & $47 \cdot 8$ & 0.2 & $50 \cdot 1$ & 0.2 & $47 \cdot 1$ & 0.2 & 49.4 & 0.3 & 48.4 & 0.4 & $49 \cdot 7$ & 0.3 & $50 \cdot 4$ & 0.4 & $52 \cdot 4$ & 0.5 \\
\hline Fat $(\mathrm{kJ})$ & $3523 \cdot 3$ & 33.5 & $2431 \cdot 3$ & 23.4 & 3668.5 & $39 \cdot 7$ & $2480 \cdot 3$ & 25.9 & 3386.5 & $78 \cdot 7$ & $2550 \cdot 6$ & $58 \cdot 2$ & $3093 \cdot 2$ & $50 \cdot 6$ & $2213 \cdot 8$ & $49 \cdot 0$ \\
\hline Fat $(\%)$ & 32.5 & 0.2 & $32 \cdot 6$ & 0.2 & 33.2 & 0.2 & 33.1 & 0.2 & 32.5 & 0.3 & 33.1 & 0.3 & 29.7 & 0.3 & $30 \cdot 7$ & 0.4 \\
\hline Protein (kJ) & $1631 \cdot 8$ & $12 \cdot 1$ & $1102 \cdot 5$ & $10 \cdot 0$ & $1651 \cdot 4$ & $15 \cdot 9$ & $1106 \cdot 2$ & $13 \cdot 4$ & $1532 \cdot 2$ & $30 \cdot 1$ & $1108 \cdot 8$ & $21 \cdot 3$ & $1603 \cdot 7$ & $21 \cdot 8$ & $1082 \cdot 0$ & $20 \cdot 1$ \\
\hline Protein (\%) & $15 \cdot 6$ & 0.1 & $15 \cdot 4$ & 0.1 & 15.5 & $0 \cdot 1$ & $15 \cdot 3$ & $0 \cdot 1$ & $15 \cdot 4$ & 0.2 & $15 \cdot 1$ & 0.2 & $15 \cdot 9$ & $0 \cdot 1$ & $15 \cdot 9$ & 0.2 \\
\hline Alcohol (kJ) & $463 \cdot 2$ & $16 \cdot 7$ & 169.9 & $12 \cdot 6$ & 483.3 & $19 \cdot 7$ & $191 \cdot 2$ & $16 \cdot 3$ & $395 \cdot 8$ & 38.5 & $182 \cdot 4$ & $24 \cdot 7$ & 437.6 & $36 \cdot 8$ & $82 \cdot 4$ & 13.4 \\
\hline Alcohol (\%) & $4 \cdot 1$ & 0.1 & $2 \cdot 0$ & 0.1 & $4 \cdot 2$ & 0.2 & $2 \cdot 3$ & 0.2 & 3.7 & 0.3 & $2 \cdot 1$ & 0.3 & 3.9 & 0.3 & $1 \cdot 1$ & 0.2 \\
\hline \multicolumn{17}{|l|}{ Obese } \\
\hline Total energy (kJ) & $10628 \cdot 6$ & $89 \cdot 1$ & $7598 \cdot 6$ & 54.4 & 10779.2 & $108 \cdot 4$ & 7701.9 & 69.5 & $9919 \cdot 8$ & $159 \cdot 0$ & $7482 \cdot 2$ & 88.7 & $10415 \cdot 2$ & $160 \cdot 2$ & $7317 \cdot 8$ & 96.7 \\
\hline Carbohydrate (kJ) & $4932 \cdot 1$ & $46 \cdot 0$ & $3745 \cdot 1$ & $26 \cdot 8$ & $4930 \cdot 8$ & 54.8 & 3735.5 & $35 \cdot 1$ & $4681 \cdot 1$ & 92.5 & 3738.0 & $45 \cdot 6$ & 5058.5 & $78 \cdot 2$ & $3795 \cdot 3$ & 52.7 \\
\hline Carbohydrate (\%) & $46 \cdot 7$ & 0.2 & $49 \cdot 6$ & 0.2 & 45.9 & 0.2 & 48.7 & 0.3 & 47.4 & 0.4 & $50 \cdot 2$ & 0.3 & $49 \cdot 1$ & 0.4 & $52 \cdot 1$ & 0.4 \\
\hline Fat $(\mathrm{kJ})$ & $3673 \cdot 1$ & $35 \cdot 6$ & $2598 \cdot 3$ & $29 \cdot 3$ & $3800 \cdot 7$ & 44.8 & 2689.9 & $37 \cdot 2$ & $3330 \cdot 9$ & $58 \cdot 2$ & $2522 \cdot 1$ & 41.8 & 3321.3 & 79.5 & $2315 \cdot 4$ & 46.4 \\
\hline Fat $(\%)$ & $34 \cdot 2$ & 0.2 & 33.6 & 0.2 & 34.9 & 0.2 & 34.4 & $0 . \overline{2}$ & 33.3 & $0 . \overline{3}$ & 33.2 & 0.3 & 31.4 & 0.4 & 31.2 & 0.4 \\
\hline Protein (kJ) & 1651.4 & $13 \cdot 8$ & $1156 \cdot 9$ & $10 \cdot 5$ & $1678 \cdot 6$ & $17 \cdot 6$ & $1177 \cdot 0$ & $14 \cdot 6$ & $1508 \cdot 3$ & $26 \cdot 4$ & $1105 \cdot 0$ & $13 \cdot 8$ & $1636 \cdot 4$ & $24 \cdot 3$ & $1144 \cdot 7$ & $18 \cdot 8$ \\
\hline Protein (\%) & 15.9 & 0.1 & $15 \cdot 6$ & 0.1 & $15 \cdot 9$ & 0.1 & $15 \cdot 7$ & 0.1 & $15 \cdot 7$ & 0.2 & $15 \cdot 2$ & 0.1 & $16 \cdot 1$ & 0.2 & $16 \cdot 0$ & 0.2 \\
\hline Alcohol (kJ) & 372.4 & 21.3 & $98 \cdot 3$ & 7.5 & $369 \cdot 0$ & $27 \cdot 6$ & $100 \cdot 0$ & $10 \cdot 0$ & 399.6 & 34.7 & 117.6 & $12 \cdot 6$ & 398.7 & 31.8 & $62 \cdot 8$ & 10.0 \\
\hline Alcohol (\%) & $3 \cdot 2$ & 0.2 & 1.2 & $0 \cdot 1$ & $3 \cdot 2$ & 0.2 & 1.2 & 0.1 & 3.6 & 0.3 & 1.4 & 0.2 & 3.4 & 0.3 & 0.7 & 0.1 \\
\hline
\end{tabular}

NHANES, National Health and Nutrition Examination Survey.

*NHANES 1999-2010 multiyear complex survey design was incorporated in estimations. 
respectively, compared with $47.1 \%$ and $49.4 \%$ among overweight Caucasian men and women. In contrast, energy from fat accounted for $29.7 \%$ and $30.7 \%$ of daily total energy intake among overweight Hispanic men and women, respectively, compared with $33.2 \%$ and $33.1 \%$ among their Caucasian counterparts. Among the female population, Hispanics had the lowest proportion of energy intake from alcohol (1.9\%, $1.1 \%$, and $0.7 \%$ among normal-weight, overweight and obese Hispanic women).

Table 3 reports the estimated change in daily total energy intake associated with a $1 \%$ pairwise substitution in composition between carbohydrate, fat and protein intake. Across all population subgroups stratified by sex, race/ethnicity and body weight status, substituting protein or carbohydrate for fat and substituting protein for carbohydrate were associated with decreased daily energy intake, with the largest effect resulting from substituting protein for fat. A $1 \%$ increase in the percentage of energy from protein substituted for a $1 \%$ decrease in the percentage of energy from fat was associated with a decrease in daily total energy intake of 268.2 (95\% CI 169.0, 367.4) kJ, 289.5 (95\% CI 215.9, 363.2) $\mathrm{kJ}$ and 293.7 (95\% CI 210.0, $377.4) \mathrm{kJ}$ among normal-weight, overweight and obese men, and 177.4 (95\% CI 130.5, 224.3) kJ, 188.7 (95\% CI 139.3, 238.1) kJ and 204.2 (95\% CI 158.2, 250.2) kJ among normalweight, overweight and obese women, respectively. A $1 \%$ increase in the percentage of energy from protein substituted for a $1 \%$ decrease in the percentage of energy from carbohydrate was associated with a decrease in daily total energy intake of $159 \cdot 0$ (95\% CI 59.8, 258.2) kJ, 183.3 (95\% CI 110.5, 256.1) kJ and 199.6 (95\% CI 115.9, 283.3) kJ among normal-weight, overweight and obese men, and $117 \cdot 2$ (95\% CI $70 \cdot 3,164.0) \mathrm{kJ}, 128.9$ (95\% CI 79.5, 178.2) kJ and 134.3 (95\% CI 88.3, 180.3) kJ among normal-weight, overweight and obese women, respectively. A $1 \%$ increase in the percentage of energy from carbohydrate substituted for a $1 \%$ decrease in the percentage of energy from fat was associated with a decrease in daily total energy intake of $115 \cdot 1$ (95\% CI 15.9, 214.2) kJ, $110 \cdot 5$ (95\% CI 36.8, 184.1) $\mathrm{kJ}$ and 94.6 (95\% CI 10.9, 178.2) kJ among normal-weight, overweight and obese men, and 59.0 (95\% CI $12 \cdot 1$, 105.9) kJ, 63.2 (95\% CI 13.0, 113.4) kJ and 71.5 (95\% CI 25.5, 117.6) kJ among normal-weight, overweight and obese women, respectively. In contrast, substituting fat or carbohydrate for protein and substituting fat for carbohydrate were associated with elevated daily total energy intake.

The relationship between macronutrient composition and daily total energy intake varied substantially across sex, race/ethnicity and body weight status. Among the male population, daily total energy intake among obese Hispanics appeared to decrease the most following a $1 \%$ increase in the percentage of energy from protein substituted for a $1 \%$ decrease in the percentage of energy from fat (351.9; $95 \%$ CI $174 \cdot 1,111.3 \mathrm{~kJ})$ or from carbohydrate $(217 \cdot 1 ; 95 \% \mathrm{CI}$ $40 \cdot 2,394 \cdot 1 \mathrm{~kJ}$ ), whereas daily total energy intake among normal-weight African Americans tended to decrease the most following a $1 \%$ increase in the percentage of energy from carbohydrate substituted for a $1 \%$ decrease in the percentage of energy from fat (148.1; $95 \%$ CI $-109 \cdot 2$, $405.4 \mathrm{~kJ})$. Among the female population, daily total energy intake of normal-weight Hispanics tended to decrease the most following a $1 \%$ increase in the percentage of energy from protein substituted for a $1 \%$ decrease in the percentage of energy from fat $(229 \cdot 3$; $95 \%$ CI $113.8,344.8 \mathrm{~kJ})$ or from carbohydrate (149.0; $95 \% \mathrm{CI} 33.5,264.4 \mathrm{~kJ})$, whereas daily total energy intake among normal-weight African Americans seemed to decrease the most following a $1 \%$ increase in the percentage of energy from carbohydrate substituted for a $1 \%$ decrease in the percentage of energy from fat (107.5; $95 \%$ CI 89.1, 304.2 kJ).

To understand the clinical importance of a substantial compositional modification in diet, we calculated the change in daily total energy intake resulting from a $10 \%$ increase in the percentage of energy from protein at the expense of a $10 \%$ decrease in the percentage of energy from fat (or carbohydrate), and from a $10 \%$ increase in the percentage of energy from carbohydrate at the expense of a $10 \%$ decrease in the percentage of energy from fat (data not shown). A $10 \%$ increase in the percentage of energy from protein substituted for a $10 \%$ decrease in the percentage of energy from fat was associated with a decrease in daily total energy intake of $2892 \cdot 8$ (95\% CI 2791.1, 2994.1) kJ, $2992 \cdot 8(95 \%$ CI 2919.6, 3066.0) kJ and 3404.9 (95\% CI 3316.2, 3493.6) $\mathrm{kJ}$ among normal-weight, overweight and obese men, and $2086 \cdot 6$ (95\% CI 2035.5, 2137.6) kJ, 1962.3 (95\% CI 1912.9, 2012.5) $\mathrm{kJ}$ and 2237.6 (95\% CI 2188.7, 2286.6) kJ among normal-weight, overweight and obese women, respectively. A $10 \%$ increase in the percentage of energy from protein substituted for a $10 \%$ decrease in the percentage of energy from carbohydrate was associated with a decrease in daily total energy intake of $1935 \cdot 1$ (95\% CI 1835.5, 2034.7) kJ, 2028.4 (95\% CI 1955.6, 2101.2) kJ and $2170 \cdot 7$ (95\% CI 2087 , 2254.3) kJ among normal-weight, overweight and obese men, and 1242.2 (95\% CI 1195.0, 1289.1) kJ, 1406.7 (95\% CI $1358.5,1454.4) \mathrm{kJ}$ and 1482.0 (95\% CI 1433.4, 1530.5) kJ among normal-weight, overweight and obese women, respectively. A $10 \%$ increase in the percentage of energy from carbohydrate substituted for a $10 \%$ decrease in the percentage of energy from fat was associated with a decrease in daily total energy intake of $1559 \cdot 8$ (95\% CI 1456.0, 1664.0) $\mathrm{kJ}, 1381 \cdot 1$ (95\% CI 1304.2, 1457.7) kJ and 1320.1 (95\% CI $1231.8,1408.3) \mathrm{kJ}$ among normal-weight, overweight and obese men, and $755 \cdot 6$ (95\% CI 706.3, 805.4) kJ, 910.4 (95\% CI 856.9, 964.4) kJ and 913.4 (95\% CI 864.8, 961.5) kJ among normal-weight, overweight and obese women, respectively.

\section{Discussion}

The widespread presence of overweight/obesity, combined with the growing proportion of adults attempting weight 
Table 3 Estimated changes in daily total energy intake associated with a $1 \%$ pairwise substitution in composition between carbohydrate, fat and protein intake by sex, race/ethnicity and body weight status: US adults aged 20 years and older ( $n$ 27 589), NHANES 1999-2010

\begin{tabular}{|c|c|c|c|c|c|c|c|c|c|c|c|c|c|c|c|c|}
\hline \multirow[b]{3}{*}{ Variable* $^{*}$} & \multicolumn{4}{|c|}{ All } & \multicolumn{4}{|c|}{ Caucasian } & \multicolumn{4}{|c|}{ African American } & \multicolumn{4}{|c|}{ Hispanic } \\
\hline & \multicolumn{2}{|c|}{ Male } & \multicolumn{2}{|c|}{ Female } & \multicolumn{2}{|c|}{ Male } & \multicolumn{2}{|c|}{ Female } & \multicolumn{2}{|c|}{ Male } & \multicolumn{2}{|c|}{ Female } & \multicolumn{2}{|c|}{ Male } & \multicolumn{2}{|c|}{ Female } \\
\hline & Mean & SE & Mean & SE & Mean & SE & Mean & SE & Mean & SE & Mean & $\mathrm{SE}$ & Mean & SE & Mean & SE \\
\hline \multicolumn{17}{|c|}{ Normal weight } \\
\hline$P \uparrow F \downarrow t$ & $-268 \cdot 2$ & $50 \cdot 6$ & -177.4 & $23 \cdot 8$ & $-270 \cdot 3$ & $73 \cdot 2$ & -175.7 & $29 \cdot 7$ & $-286 \cdot 2$ & $131 \cdot 0$ & -199.6 & $100 \cdot 8$ & -265.3 & 114.2 & $-229 \cdot 3$ & 59.0 \\
\hline$P \downarrow F \uparrow \ddagger$ & $264 \cdot 0$ & $50 \cdot 6$ & $170 \cdot 3$ & $23 \cdot 4$ & $260 \cdot 2$ & $72 \cdot 8$ & $168 \cdot 2$ & $29 \cdot 3$ & $262 \cdot 3$ & 131.0 & 189.5 & $99 \cdot 2$ & 292.9 & $113 \cdot 4$ & $231 \cdot 8$ & $59 \cdot 4$ \\
\hline$P \uparrow C \downarrow \S$ & -159.0 & $50 \cdot 6$ & $-117 \cdot 2$ & 23.8 & -169.5 & $73 \cdot 2$ & $-122 \cdot 6$ & $29 \cdot 7$ & $-143 \cdot 1$ & 130.5 & -92.9 & $100 \cdot 4$ & -148.5 & $113 \cdot 8$ & $-149 \cdot 0$ & 59.0 \\
\hline$P \downarrow C \uparrow \|$ & 151.5 & $50 \cdot 6$ & 115.9 & 23.4 & $160 \cdot 2$ & $72 \cdot 8$ & 119.7 & $29 \cdot 3$ & 118.4 & 131.4 & 83.3 & $100 \cdot 0$ & 158.2 & 113.8 & $152 \cdot 7$ & $59 \cdot 4$ \\
\hline$C \uparrow F \downarrow \downarrow$ & $-115 \cdot 1$ & $50 \cdot 6$ & $-59 \cdot 0$ & 23.8 & -105.9 & $73 \cdot 2$ & $-52 \cdot 7$ & $29 \cdot 7$ & $-148 \cdot 1$ & 131.4 & -107.5 & $100 \cdot 4$ & $-127 \cdot 6$ & $114 \cdot 2$ & $-80 \cdot 8$ & $59 \cdot 4$ \\
\hline$C \downarrow F \uparrow^{\star *}$ & 106.7 & $50 \cdot 6$ & 55.6 & 23.4 & 95.0 & $72 \cdot 8$ & $49 \cdot 0$ & $29 \cdot 3$ & 138.9 & $130 \cdot 1$ & 105.4 & 99.6 & $122 \cdot 2$ & 113.4 & 78.7 & $59 \cdot 4$ \\
\hline \multicolumn{17}{|l|}{ Overweight } \\
\hline $\mathrm{P} \uparrow \mathrm{F} \downarrow$ & -289.5 & $37 \cdot 7$ & $-188 \cdot 7$ & $25 \cdot 1$ & -315.5 & 55.2 & $-176 \cdot 1$ & 34.3 & -285.8 & 110.9 & $-200 \cdot 0$ & $82 \cdot 8$ & -236.0 & $65 \cdot 7$ & $-214 \cdot 2$ & $48 \cdot 1$ \\
\hline$P \downarrow F \uparrow$ & 287.4 & $37 \cdot 7$ & $187 \cdot 0$ & 25.5 & 311.7 & 54.8 & $174 \cdot 1$ & 34.3 & 277.0 & $110 \cdot 0$ & $191 \cdot 2$ & $82 \cdot 4$ & 196.6 & $63 \cdot 2$ & $215 \cdot 1$ & 48.5 \\
\hline$P \uparrow C \downarrow$ & -183.3 & 37.2 & -128.9 & $25 \cdot 1$ & -215.5 & $55 \cdot 2$ & $-126 \cdot 8$ & 34.3 & -163.6 & 110.5 & $-121 \cdot 3$ & $82 \cdot 8$ & -95.4 & 64.9 & $-144 \cdot 3$ & $48 \cdot 1$ \\
\hline$P \downarrow C \uparrow$ & 179.1 & 37.7 & 125.9 & 25.5 & 213.4 & $55 \cdot 2$ & $124 \cdot 3$ & 34.3 & 146.0 & 110.5 & $106 \cdot 7$ & 82.4 & 79.9 & 64.0 & 143.5 & 48.5 \\
\hline$C \uparrow F \downarrow$ & -110.5 & $37 \cdot 7$ & $-63 \cdot 2$ & $25 \cdot 5$ & $-101 \cdot 7$ & $55 \cdot 2$ & $-52 \cdot 7$ & 34.7 & $-131 \cdot 4$ & 110.9 & $-86 \cdot 6$ & $82 \cdot 8$ & -133.9 & $65 \cdot 3$ & $-72 \cdot 8$ & 48.5 \\
\hline$C \downarrow F \uparrow$ & $104 \cdot 2$ & $37 \cdot 2$ & $57 \cdot 3$ & $25 \cdot 1$ & $96 \cdot 7$ & 54.8 & $46 \cdot 9$ & $34 \cdot 3$ & $121 \cdot 8$ & $110 \cdot 0$ & 76.6 & $82 \cdot 4$ & 123.0 & $63 \cdot 6$ & 68.6 & $48 \cdot 1$ \\
\hline \multicolumn{17}{|l|}{ Obese } \\
\hline $\mathrm{P} \uparrow \mathrm{F} \downarrow$ & -293.7 & $42 \cdot 7$ & $-204 \cdot 2$ & 23.4 & $-285 \cdot 3$ & 61.5 & $-47 \cdot 3$ & $36 \cdot 4$ & $-300 \cdot 8$ & 97.9 & -218.4 & $53 \cdot 1$ & -351.9 & $90 \cdot 8$ & $-207 \cdot 1$ & $47 \cdot 7$ \\
\hline$P \downarrow F \uparrow$ & 282.8 & $42 \cdot 7$ & 200.0 & 23.0 & $280 \cdot 3$ & 61.5 & $46 \cdot 0$ & $36 \cdot 0$ & $265 \cdot 7$ & 95.0 & $210 \cdot 0$ & 51.9 & 351.9 & $90 \cdot 8$ & $196 \cdot 2$ & $47 \cdot 7$ \\
\hline$P \uparrow C \downarrow$ & -199.6 & $42 \cdot 7$ & -134.3 & 23.4 & -201.7 & $61 \cdot 1$ & $-31 \cdot 7$ & $36 \cdot 4$ & $-198 \cdot 3$ & $97 \cdot 1$ & -143.9 & 52.7 & $-217 \cdot 1$ & 90.4 & $-139 \cdot 3$ & $47 \cdot 7$ \\
\hline$P \downarrow C \uparrow$ & 195.4 & $42 \cdot 7$ & 131.0 & $23 \cdot 0$ & 197.9 & 61.5 & 30.7 & $36 \cdot 0$ & 193.7 & 95.8 & $146 \cdot 0$ & $52 \cdot 3$ & $214 \cdot 2$ & 91.6 & $131 \cdot 0$ & $48 \cdot 1$ \\
\hline$C \uparrow F \downarrow$ & -94.6 & $42 \cdot 7$ & -71.5 & 23.4 & $-86 \cdot 2$ & 61.5 & $-15 \cdot 8$ & $36 \cdot 4$ & -94.1 & $97 \cdot 1$ & $-72 \cdot 8$ & $52 \cdot 7$ & -143.1 & 91.6 & -69.5 & $48 \cdot 1$ \\
\hline$C \downarrow F \uparrow$ & $86 \cdot 2$ & $42 \cdot 3$ & 66.9 & $23 \cdot 0$ & 79.9 & 61.5 & $15 \cdot 2$ & $36 \cdot 0$ & $80 \cdot 3$ & $95 \cdot 4$ & 65.7 & $52 \cdot 3$ & 129.7 & 90.4 & 63.6 & $47 \cdot 3$ \\
\hline
\end{tabular}

NHANES, National Health and Nutrition Examination Survey.

"Changes in daily total energy intake were estimated using Scheffé linear mixture models, accounting for NHANES 1999-2010 multiyear complex survey design.

†P $\uparrow \mathrm{F} \downarrow$ denotes a $1 \%$ increase in the percentage of energy from protein substituted for a $1 \%$ decrease in the percentage of energy from fat.

†P $\downarrow \mathrm{F} \uparrow$ denotes a $1 \%$ decrease in the percentage of energy from protein substituted for a $1 \%$ increase in the percentage of energy from fat.

§P $\uparrow \mathrm{C} \downarrow$ denotes a $1 \%$ increase in the percentage of energy from protein substituted for a $1 \%$ decrease in the percentage of energy from carbohsydrate.

IIP $\downarrow C$ C $\uparrow$ denotes a $1 \%$ decrease in the percentage of energy from protein substituted for a $1 \%$ increase in the percentage of energy from carbohydrate

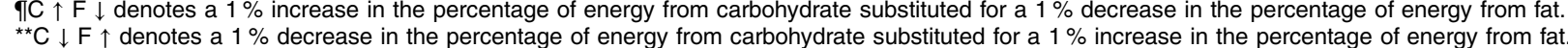


loss, underlines the need to identify effective intervention strategies to support metabolic health and long-term weight control in the US adult population. Findings from the current population-level study confirmed the relationship between dietary macronutrient composition and daily total energy intake that has been reported in randomized experiments $^{(12,29)}$. In particular, substituting protein for fat tends to be most effective in reducing total energy intake across all sub-populations by sex, race/ethnicity and body weight status, although the exact effect size differs. The consumption of protein is an established dietary practice for improved appetite control and satiety when compared with the ingestion of an isoenergetic amount of carbohydrate or $\mathrm{fat}^{(30-33)}$. As such, a diet that includes a modestly elevated protein intake at the expense of the other macronutrients may lead to weight loss through reduced daily energy consumption $^{(34)}$. Moreover, dietary protein intake provides the amino acid substrates needed for maintenance, repair and synthesis of muscle proteins ${ }^{(35)}$. The maintenance of skeletal muscle mass, and the associated preservation of $\mathrm{BMR}$, are necessary for long-term weight stability as well as to minimize the likelihood of weight gain $^{(7,36,37)}$.

Simulation results indicate that a $10 \%$ pairwise substitution in macronutrient composition has a substantial impact on daily total energy intake, and in general the effect size increases with weight category. Especially, a $10 \%$ increase in the percentage of energy from protein substituted for a $10 \%$ decrease in the percentage of energy from fat was estimated to be associated with a decrease in daily total energy intake of $25.9 \%, 28.0 \%$ and $32.0 \%$ among normalweight, overweight and obese men, and $27 \cdot 1 \%, 26.6 \%$ and $29.4 \%$ among normal-weight, overweight and obese women, respectively. The average percentage of energy from protein was $15.4 \%$ in the US adult population during 1999-2010, and thus a 10\% increase would be arguably quite large (a relative increase by $64.9 \%$ from baseline rate). However, this percentage is within the acceptable macronutrient distribution range for dietary protein, which is $10 \%$ to $35 \%$ of energy from protein for adults ${ }^{(38)}$. In fact, evidence suggests that the current protein reference daily intake (RDA), which is essentially represented by the lower distribution range of the acceptable macronutrient distribution range, is insufficient to cover the daily needs for protein with ageing ${ }^{(39,40)}$, programmes of exercise training $^{(41)}$ and/or during periods of reduced dietary energy intake ${ }^{(42,43)}$. A systematic review cautioned against excessive protein intake greater than two times of the protein RDA ( $130 \mathrm{~g}$ for adult men and women) for potential urinary Ca loss and bone loss, especially among those with diabetes mellitus or predisposed to nephrolithiasis or kidney disease ${ }^{(44)}$. However, evidence regarding the potential detrimental impact of dietary protein on bone or renal health is sparse ${ }^{(45-47)}$. In contrast, the consumption of high(er) protein diets is more commonly associated with positive health outcomes (e.g. improved bone health and/or reduced risk for CVD $)^{(48,49)}$, unless already at risk for the development of kidney failure ${ }^{(50)}$. Given the much lower actual daily protein intake among US adults $(82.6 \mathrm{~g})$ relative to the recommended level, a $10 \%$ increase in the percentage of energy from protein is unlikely to result in severe adverse health outcomes in the healthy, US adult population.

The present work confirmed findings from previous studies on the heterogeneous energy intake patterns across sex and race/ethnicity ${ }^{(16-22)}$. Moreover, the relationship linking macronutrient composition to daily total energy intake appeared to differ between population subgroups stratified by sex, race/ethnicity and body weight status. Admittedly the concurrent evidence is rather preliminary and the differences are often statistically non-significant, which warrants future research and result replication. Nevertheless, it is the very first attempt to estimate sex-, racial/ ethnic- and weight-specific impact of macronutrient composition on daily energy consumption, indicating the importance of considering population heterogeneity in designing dietary guidelines and providing nutrient intake recommendations.

The beneficial health effect of protein products has been highlighted in the 2010 Dietary Guidelines for Americans ${ }^{(51)}$. Moreover, caveats are given on choosing among animalbased foods: '...some protein products, particularly some animal-based sources, are high in saturated fat, so non-fat, low-fat, or lean choices should be selected'. A possibly less emphasized point is the importance of substitution between macronutrients (protein or carbohydrate for fat, protein for carbohydrate) because fundamentally it is the total energy intake, rather than energy intake from any macronutrient alone, that impacts body weight. If increased consumption of protein products is not accompanied by a proportional reduction in fat intake, daily total energy consumption would only increase, so that the modification in dietary profile is unlikely to translate to healthier weight status.

Several limitations of the present study should be noted. Dietary intake data in NHANES are subject to underreporting and the discrepancy between estimated and selfreported energy intake appears largest among the obese respondents ${ }^{(25)}$. Sensitivity analyses indicate that this underreporting is likely to result in underestimation of the change in daily total energy intake associated with compositional variations in carbohydrate, fat and protein intake. Body weight status is based on BMI, a function of weight and height, rather than on body fatness. Although BMI has been found to be closely associated with percentage body fat measured by dual-energy X-ray absorptiometry in the NHANES, these two measures are fundamentally different and their levels of agreement could be a function of sex, age and race/ethnicity ${ }^{52,53)}$. Despite the large overall sample size, multilevel stratifications by sex, race/ethnicity and body weight status compromised the statistical precision of estimation for some subgroups. The current study is observational in design, so that the estimated relationship between daily total energy intake and macronutrient composition should be interpreted as association rather 
than causation. Within-individual variability was not considered in the estimation due to the cross-sectional study design of NHANES. NHANES is a probability sample of the US non-institutionalized population and the dietary intakes within patients in penal/mental facilities, institutionalized older adults and/or military personnel on active duty were not captured.

\section{Conclusion}

In conclusion, the present study estimated the change in daily total energy intake associated with compositional variations in carbohydrate, fat and protein intake among US adults using multiple years of data from a large nationally representative survey. For all sub-populations by sex, race/ ethnicity and body weight status, substituting protein or carbohydrate for fat and substituting protein for carbohydrate contributed to decreased daily energy intake, with the largest effect resulting from substituting protein for fat. The relationship between macronutrient composition and daily energy intake appeared heterogeneous across population subgroups. Policies promoting higher daily protein intake at the expense of lower fat intake could be effective in reducing total energy intake in the US adult population.

\section{Acknowledgements}

Financial support: This research received no specific grant from any funding agency in the public, commercial or notfor-profit sectors. Conflict of interest: None. Authorship: R.A. designed the study, conducted the statistical analysis and wrote the manuscript. N.A.B. contributed to modelling result interpretation and manuscript drafting. Ethics of buman subject participation: This study used de-identified public-use data and thus was exempt from human subjects review.

\section{References}

1. Villareal DT, Apovian CM, Kushner RF et al. (2005) Obesity in older adults: technical review and position statement of the American Society for Nutrition and NAASO, The Obesity Society. Am J Clin Nutr 82, 923-934.

2. An R (2014) Prevalence and trends of adult obesity in the US, 1999-2012. ISRN Obesity 2014, 185132.

3. Fryar CD, Carroll MD \& Odgen CL (2012) Prevalence of Overweight, Obesity, and Extreme Obesity Among Adults: United States, Trends 1960-1962 Through 2009-2010. Hyattsville, MD: National Centre for Health Statistics; available at http://www.cdc.gov/nchs/data/hestat/obesity_adult_09_ 10/obesity_adult_09_10.htm.

4. Wang Y \& Beydoun MA (2007) The obesity epidemic in the United States - gender, age, socioeconomic, racial/ethnic, and geographic characteristics: a systematic review and meta-regression analysis. Epidemiol Rev 29, 6-28.

5. Finkelstein EA, Trogdon JG, Cohen JW et al. (2009) Annual medical spending attributable to obesity: payer- and servicespecific estimates. Health Aff (Millwood) 28, w822-w831.
6. Behan DF, Cox SH, Lin Y et al. (2010) Obesity and its relation to mortality and morbidity costs. http://www.soa.org/ Workarea/DownloadAsset.aspx?id=30063 (accessed March 2014).

7. Lejeune MP, Kovacs EM \& Westerterp-Plantenga MS (2005) Additional protein intake limits weight regain after weight loss in humans. BrJ Nutr 93, 281-289.

8. Sacks FM, Bray GA, Carey VJ et al. (2009) Comparison of weight-loss diets with different compositions of fat, protein, and carbohydrates. $N$ Engl J Med 360, 859-873.

9. Noakes M, Keogh JB, Foster PR et al. (2005) Effect of an energy-restricted, high-protein, low-fat diet relative to a conventional high-carbohydrate, low-fat diet on weight loss, body composition, nutritional status, and markers of cardiovascular health in obese women. Am J Clin Nutr 81, 1298-1306.

10. Hooper L, Abdelhamid A, Moore HJ et al. (2012) Effect of reducing total fat intake on body weight: systematic review and meta-analysis of randomized controlled trials and cohort studies. BMJ 345, e7666.

11. Clifton PM, Keogh JB \& Noakes M (2008) Long-term effects of a high-protein weight-loss diet. Am J Clin Nutr 87, 23-29.

12. Paddon-Jones D, Westman E, Mattes RD et al. (2008) Protein, weight management, and satiety. Am J Clin Nutr 87, issue 5, 1558S-1561S.

13. Westerterp KR, Verboeket-van de Venne WP, Bouten CV et al. (1996) Energy expenditure and physical activity in subjects consuming full-or reduced-fat products as part of their normal diet. Br J Nutr 76, 785-795.

14. Ford ES \& Dietz WH (2013) Trends in energy intake among adults in the United States: findings from NHANES. Am J Clin Nutr 97, 848-853.

15. Austin GL, Ogden LG \& Hill JO (2011) Trends in carbohydrate, fat, and protein intakes and association with energy intake in normal-weight, overweight, and obese individuals: 1971-2006. Am J Clin Nutr 93, 836-843.

16. Leblanc V, Bégin C, Corneau L et al. (2014) Gender differences in dietary intakes: what is the contribution of motivational variables? J Hum Nutr Diet (Epublication ahead of print version).

17. Tarnopolsky MA (1998) Gender Differences in Metabolism: Practical and Nutritional Implications. Boca Raton, FL: CRC Press.

18. Blaak E (2001) Gender differences in fat metabolism. Curr Opin Clin Nutr Mestab Care 4, 499-502.

19. Tarnopolsky MA, Zawada C, Richmond LB et al. (2001) Gender differences in carbohydrate loading are related to energy intake. J Appl Physiol 91, 225-230.

20. Wu BN \& O'Sullivan AJ (2011) Sex differences in energy metabolism need to be considered with lifestyle modifications in humans. J Nutr Metab 2011, 391809.

21. Davy BM, Van Walleghen EL \& Orr JS (2007) Sex differences in acute energy intake regulation. Appetite 49, 141-147.

22. Wang Y \& Chen X (2011) How much of racial/ethnic disparities in dietary intakes, exercise, and weight status can be explained by nutrition- and health-related psychosocial factors and socioeconomic status among US adults? I Am Diet Assoc 111, 1904-1911.

23. Centers for Disease Control and Prevention (2013) National Health and Nutrition Examination Survey. http://www.cdc. gov/nchs/nhanes.htm (accessed March 2014).

24. Mclntosh A, McDowell M \& McNutt S (1999) Assuring quality for National Health and Nutrition Examination Survey dietary coding. J Am Diet Assoc 99, A89.

25. Archer E, Hand GA \& Blair SN (2013) Validity of US nutritional surveillance: National Health and Nutrition Examination Survey caloric energy intake data, 1971-2010. PLoS One 8, e76632.

26. Scheffé H (1958) Experiments with mixtures. J R Stat Soc Ser B 20, 344-360. 
27. Cornell JA (2011) A Primer on Experiments with Mixtures. Hoboken, NJ: Wiley.

28. Centers for Disease Control and Prevention (2014) Task 2: When and How to Construct Weights When Combining Survey Cycles. http://www.cdc.gov/nchs/tutorials/nhanes/ SurveyDesign/Weighting/Task2.htm (accessed March 2014).

29. Halton TL \& Hu FB (2004) The effects of high protein diets on thermogenesis, satiety and weight loss: a critical review. J Am Coll Nutr 23, 373-385.

30. Yancy WS Jr, Olsen MK, Guyton JR et al. (2004) A lowcarbohydrate, ketogenic diet versus a low-fat diet to treat obesity and hyperlipidemia: a randomized, controlled trial. Ann Intern Med 140, 769-777.

31. Astrup A (2005) The satiating power of protein - a key to obesity prevention? Am J Clin Nutr 82, 1-2.

32. Westerterp-Plantenga MS, Rolland V, Wilson SA et al. (1999) Satiety related to $24 \mathrm{~h}$ diet-induced thermogenesis during high protein/carbohydrate vs high fat diets measured in a respiration chamber. Eur J Clin Nutr 53, 495-502.

33. Westman EC, Yancy WS, Edman JS et al. (2002) Effect of 6-month adherence to a very low carbohydrate diet program. Am J Med 113, 30-36.

34. Tannous dit El, Khoury D, Obeid O, Azar ST et al. (2006) Variations in postprandial ghrelin status following ingestion of high-carbohydrate, high-fat, and high-protein meals in males. Ann Nutr Metab 50, 260-269.

35. Burd NA, Tang JE, Moore DR et al. (2009) Exercise training and protein metabolism: influences of contraction, protein intake, and sex-based differences. J Appl Physiol 106, 1692-1701.

36. Westerterp-Plantenga MS, Lejeune MP, Nijs I et al. (2004) High protein intake sustains weight maintenance after body weight loss in humans. Int J Obes Relat Metab Disord 28, $57-64$.

37. Layman DK, Boileau RA, Erickson DJ et al. (2003) A reduced ratio of dietary carbohydrate to protein improves body composition and blood lipid profiles during weight loss in adult women. J Nutr 133, 411-417.

38. Institute of Medicine, Food and Nutrition Board (2005) Dietary Reference Intakes for Energy, Carbohydrate, Fiber, Fat, Fatty Acids, Cholesterol, Protein, and Amino Acids. Washington, DC: National Academy Press.

39. Pennings B, Groen B, de Lange A et al. (2012) Amino acid absorption and subsequent muscle protein accretion following graded intakes of whey protein in elderly men. Am J Physiol 302, E992-E999.

40. Campbell WW, Trappe TA, Wolfe RR et al. (2001) The recommended dietary allowance for protein may not be adequate for older people to maintain skeletal muscle. J Gerontol A Biol Sci Med Sci 56, M373-M380.

41. Tarnopolsky M (2004) Protein requirements for endurance athletes. Nutrition 20, 662-668.

42. Weinheimer EM, Sands LP \& Campbell WW (2010) A systematic review of the separate and combined effects of energy restriction and exercise on fat-free mass in middleaged and older adults: implications for sarcopenic obesity. Nutr Rev 68, 375-388.

43. Krieger JW, Sitren HS, Daniels MJ et al. (2006) Effects of variation in protein and carbohydrate intake on body mass and composition during energy restriction: a metaregression 1. Am J Clin Nutr 83, 260-274.

44. Eisenstein J, Roberts SB, Dallal G et al. (2002) High-protein weight-loss diets: are they safe and do they work? A review of the experimental and epidemiologic data. Nutr Rev $\mathbf{6 0}$, 189-200.

45. Massini LA, Han H, Seifter J et al. (2014) Diet and kidney stones: myths and realities. Nutr Today 49, 32-38.

46. Kerstetter JE, Kenny AM \& Insogna KL (2011) Dietary protein and skeletal health: a review of recent human research. Curr Opin Lipidol 22, 16-20.

47. Fenton TR, Tough SC, Lyon AW et al. (2011) Causal assessment of dietary acid load and bone disease: a systematic review \& meta-analysis applying Hill's epidemiologic criteria for causality. Nutr $J \mathbf{1 0}, 41$.

48. Josse AR, Atkinson SA, Tarnopolsky MA et al. (2012) Diets higher in dairy foods and dietary protein support bone health during diet- and exercise-induced weight loss in overweight and obese premenopausal women. J Clin Endocrinol Metab 97, 251-260.

49. Santesso N, Akl EA, Bianchi M et al. (2012) Effects of higherversus lower-protein diets on health outcomes: a systematic review and meta-analysis. Eur J Clin Nutr 66, 780-788.

50. Kovesdy CP, Kopple JD \& Kalantar-Zadeh K (2013) Management of protein-energy wasting in non-dialysis-dependent chronic kidney disease: reconciling low protein intake with nutritional therapy. Am J Clin Nutr 97, 1163-1177.

51. US Department of Agriculture \& US Department of Health and Human Services (2010) Dietary Guidelines for Americans, 2010. Washington, DC: US Government Printing Office.

52. Flegal KM, Shepherd JA, Looker AC et al. (2009) Comparisons of percentage body fat, body mass index, waist circumference, and waist-stature ratio in adults. Am J Clin Nutr 89, 500-508.

53. Fernandez JR, Heo M, Heymsfield SB et al. (2003) Is percentage body fat differentially related to body mass index in Hispanic Americans, African Americans, and European Americans? Am J Clin Nutr 77, 71-75. 